\title{
Passive zones, bio-climatic design and scale hierarchic urban fabric
}

\author{
S. Salat \& L. Bourdic \\ Urban Morphology Lab, CSTB, France
}

\begin{abstract}
Bioclimatic design in cities widely relies on the optimization of the interface between the city and the outside. With this in mind, passive zones are a crucial aspect of building sustainability: the zones located less than 6 meters from the façade can benefit from natural lighting, natural ventilation and passive solar gains. The passive volume ratio of an urban structure thus widely impacts on the energy requirements associated with lighting, ventilation, cooling and heating. Based on a twofold approach, this paper shows how complex urban structures with courtyards allow optimizing passive volumes ratios. Building on a geometric model, the paper shows how the passive volume ratio increases along with the scale hierarchy of courtyards within the urban fabric. A massive tower displays a passive volume ratio of $17 \%$ whereas a fabric with 3 scales Sierpinski carpet-like urban fabric displays a passive volume ratio of $100 \%$. This geometric model is enhanced by a comparison of real urban structures. It shows that many historical urban tissues display passive volume ratios that are up to 6 times higher than in simple modernist urban fabrics. These results on passive volumes are then put in perspective with the buildings envelope/volume ratio, leading to the introduction of a climatic-dependant trade-off.

Keywords: passive zones, urban morphology, scale hierarchy, urban fabric, bio-climatic design.
\end{abstract}

\section{Introduction}

Modernism led to the near complete disappearance of courtyard types, which were supplanted by freestanding buildings. This paper undertakes an environmental comparison of these two main families of urban types. Compared to the freestanding towers or pavilions, exposed on all sides, courtyards 
integrated into a continuous fabric create a sheltered exterior space, that can be appropriated by the residents and that offers great potential for passive energy gains. This paper investigates the issue of building energy consumption on the neighborhood and district scale. On this scale, the city can be analysed as a large membrane separating the inside and the outside. One of the many ways to tackle the issue of building energy consumption is thus investigate the structure of this interface and to find ways to optimise it. The first section of the paper shows how fractal theory provides innovative tools to optimise this interface. Based on 6 geometric neighborhood patterns, the following section shows how the fractalisation of court textures allows an optimisation of the passive volume ratios on the neighborhood scale. These results are then compared with 4 existing urban fabrics. Putting these passive volume aspects into perspective with the building envelope/volume ratio, the last section shows how the trade-off between both is climatic dependant.

\section{The fractal optimization of court textures}

Natural structures respond to laws of optimized exchanges across membranes. In urban forms, courtyard textures and their implications in terms of energy have been investigated by several authors [1,2]. They respond to the need of bioclimatic optimization. This is why they almost universally characterize historical cities from China [2] to India and from the Islamic world [3] to Greece [4] and Italy. They did not disappear until the emergence of artificial means of controlling interior environments, means that are very costly in fossil fuels.

We shall illustrate this aspect by a simple example. Suppose that a system needs to increase energy gains from the environment, across a membrane. This is the case for natural lighting and passive solar gains, and this is also the case today for the potential to capture photovoltaic energy through the building's envelope. Energy gains (and bioclimatic exchanges, more generally) are proportional to the surface area of the membrane. Consequently, the system necessitates maximizing a quantity of topological dimension $\mathrm{D}=2$. Exchanges of energy, air, and light take place across the external surface of the body. Optimization would thus lead to an increase in the body's size. However, the result of such a process is negative for energy gains: the increase in size by a factor $\rho$ increases the surface by $\rho^{2}$, but also the volume by $\rho^{3}$, so that the energy by unit of volume decreases as $1 / \rho$.

This decrease was advocated in the 1970s by thermal engineers in cold countries for the purpose of limiting heat losses and constructing airtight buildings. Rather than reducing heat loss by sacrificing solar gains, lighting and natural ventilation, a bioclimatic architecture must on the contrary resolve the following optimization problem: Is it possible to optimize the exchange surface without increasing the body's volume? The only solution for increasing the bioclimatic exchanges (or the energy capture potential) is to increase the surface inside the given limits of the building via fractal complexification. At a given scale, the increase displays a limit that can only be exceeded by a new 
complexification at a smaller scale, and so on. The fractal iteration stops when the advantages are balanced out by other constraints or physical limits.

It would be interesting to examine in vernacular architecture whether the variation of the size of courtyards according to the different climates, results from a process of energy exchange optimization across the membranes. The process of complexification optimizes both the passive volume and the volumetric compactness $(\mathrm{S} / \mathrm{V})$, as we have observed on blocks in Turin that starting from the Roman foundation have evolved toward a significant inner complexity and have strongly increased their exchange surfaces (40 km of façades on the street and $16 \mathrm{~km}$ on the courtyards in an $710 \times 770$ meter selection corresponding to the old Roman colony) without degrading their thermal performance. Conversely, the square blocks in Barcelona, designed on a grid twice the size of Turin's (113 x 113 meters rather than $70 \times 70$ meters) and which, after only a century and a half of existence, densified without complexifying like those in Turin, two thousand years old, do not display the same optimal character.

We could study from this perspective dozens of different types of urban textures with courtyards because they not only offer the most bioclimatic advantages but also the greatest flexibility to optimize energy exchanges through the membranes, depending on the climate, the season, and the time of day, because membranes themselves can also be fractalized and transformed into porous surfaces filtering air and light (as Indian, Islamic, and Chinese architecture show). The fractality of Islamic architecture, with its countless openings, from the Arab countries to India, evinces a desire to increase the number of envelope surface components almost ad infinitum and to create porous membranes through which air moves. They filter the sunlight, subduing its intensity and attenuating its heat. What we learn both from the history of urban and architectural forms and from recent calculations is that the form of an urban texture, and the more or less porous and variable conception of the membranes that make up the envelopes, depend above all on latitude and climate.

\section{Passive volumes}

The concept of passive zone is described in the LT-method [5, 6] as being the area in the building within a distance from a perimeter wall, usually between 6 and 8 meters, depending on the floor to ceiling height (see Figure 1). These passive zones benefit from natural lighting and natural ventilation, but also from useful solar gains in winter. The energy consumption associated with lighting and ventilation is thus expected to be lower in these zones, an important part of lighting and ventilation being 'free'. On the contrary, these zones suffer from heat loss through the envelope and from unwanted solar gains in summer.

But as building technologies improve significantly at the present time, notably concerning glazing and insulation, the share of this unwanted phenomenon in the overall energy consumption figure will tend to diminish significantly in the future. In the office buildings, energy consumption is mostly 


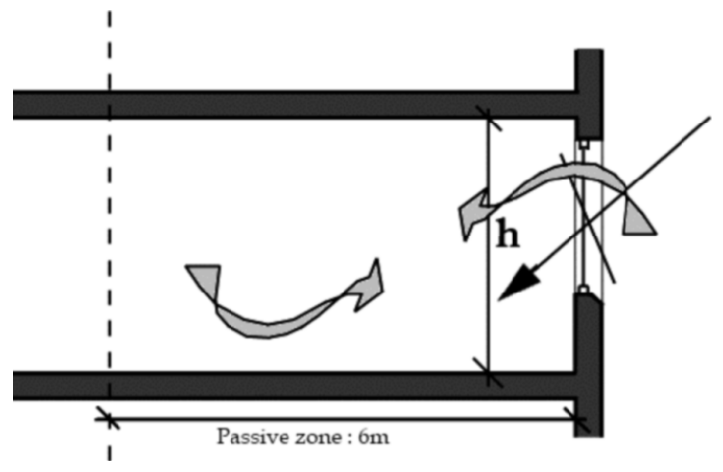

Figure 1: $\quad$ The passive zone is located less than 6 meters from the façade [5].

associated with lighting, ventilating and cooling, even though the outside temperature is low. Concerning residential buildings, improved glazing and insulation will diminish the share of heating in the overall energy consumption figure in a close future. As it is already the case in office buildings, the share of ventilation, lighting and cooling will increase.

Strategically speaking, the role of passive zones will become more and more significant in the coming years and decades, as the benefits from improvements of insulation and glazing will become marginal. The more passive zones in the building, the better. Unfortunately, it is much harder to improve the passive volume ratio - the ratio of the volume of passive zones over the total volume - of an already built building than its insulation. This ratio entirely depends on the original form of the building. If the passive volume ratio of a building is low, it is almost impossible to change it, but to destroy and rebuilt. Whereas improving insulation or glazing is a matter of months or years, improving passive volume ratios is a matter of several decades, i.e. the lifespan of the building.

The approach presented in this paper rests upon an ability to scale up urban issues. Passive volume ratios are a characteristic on the building scale. But considering this issue from the neighborhood or the district scale provides interesting insights. The following analysis is based on the neighborhood scale. It aims at showing how passive volume ratio may increase as urban fabric becomes more complex. In the six situations, the zone under consideration is a 200x200m square, in which the building occupies $70 \%$ of the available floor area. The first three examples display simple urban organizations on which most of modernist cities have been based.

Figure 2 displays a mono-block structure, typically a tower. Passive zones are in green whereas non-passive zones are in black. The passive volume ratio (PVR) is only 17\%, which is extremely low and leads to high energy consumptions notably for lighting, ventilation and cooling (even in cold climates). The reader will certainly notice that unfortunately most of the office buildings - where energy consumption is mainly associated with lighting, ventilation and cooling - are towers... 


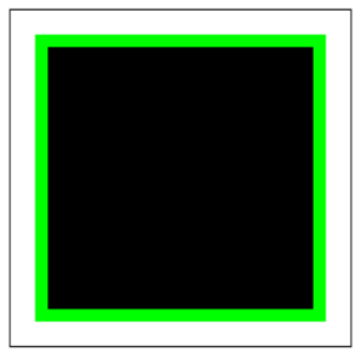

Figure 2: $\quad$ One block, PVR=17\%.

Figures 3 and 4 display two other structures, with the exact same floor area ratio. The passive volume ratio remains below $60 \%$ in both cases.

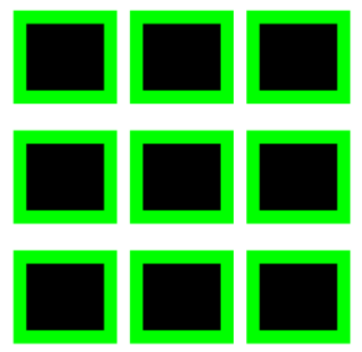

Figure 3: 9 blocks, PVR=46\%. Figure 4: Linear buildings, $\mathrm{PVR}=58 \%$.

Figure 5, 6 and 7 show three structures based on square courtyards, with a growing complexity. The construction is directly inspired from fractal theory, and more precisely from a Sierpinski carpet. Several authors have highlighted the potential of fractal theory to better grasp urban complexity [7-9] and to optimize urban structures $[10,11]$. Figure 5 displays a massive building with only one block, with one big courtyard: the passive volume ratio is low. In figure 6 , a second level of smaller courtyards has been added in the building. This leads to an almost doubling of the passive volume ratio. Finally, another level of courtyards is added in the building (Figure 7), leading to a passive volume ratio of $100 \%$.

This simple geometric analysis shows that complex urban fabrics, based here on fractal theory, display a much higher passive volume ratio than simple ones. Fractal theory is a way to optimize the "urban membrane" - the interface between the inside and the outside. In figure 7 , the pattern is distributed over three scales, instead of one in figure 1 . The careful reader will then certainly notice that the multiplicity-size distribution of courtyards in figure 7 follows a power law. Further research is currently carried out to understand how size and 

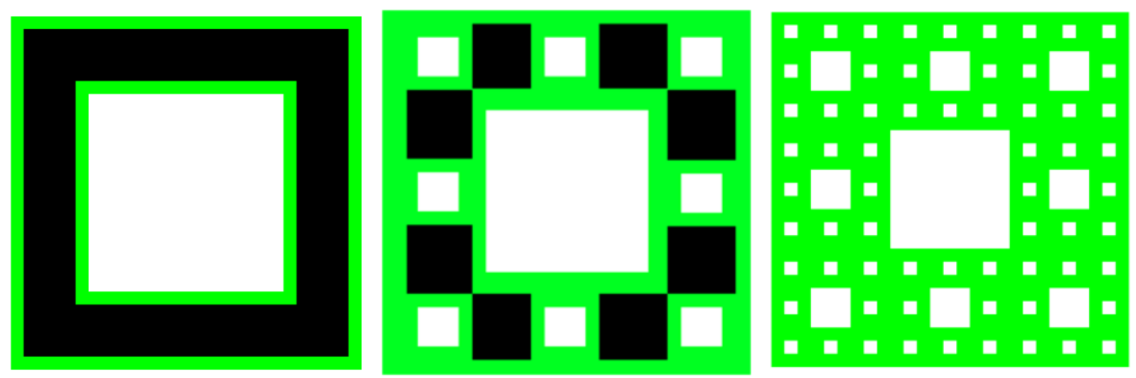

Figure 5: One courtyard, Figure 6: 2 levels of PVR=33\%. courtyards, $\mathrm{PVR}=60 \%$.

Figure 7: 3 levels of courtyards, PVR $=100 \%$.

scale hierarchy of courtyards impact on energy consumption patterns according to the different climates.

Pushing further this geometric analysis, we have investigated numerous urban tissues, historical and modernist ones, in cold and hot climates. When analyzing real cities, the same kind of results emerge: the more complex the urban tissue, the higher the passive volume ratio. The four following figures display two modernist districts (800x800 m squares) and two historical ones. Passive zones are in dark grey, whereas non passive zones are in light grey. The two first districts are made of simple blocks, without any courtyard. In Shanghai Lujiazui Central Business District (Figure 8), elements are so massive that the passive volume ratio is smaller than $50 \%$. In Thianhe district (Figure 9), there are two predominant scales of buildings. The small ones have an acceptable passive volume ratio, but the big ones have a dramatically low one, leading to an average passive volume ratio of $66 \%$.

In the two historical urban tissues, Shanghai's Lilongs in figure 10 and a Parisian district in figure 11, there are still some big elements. But they are

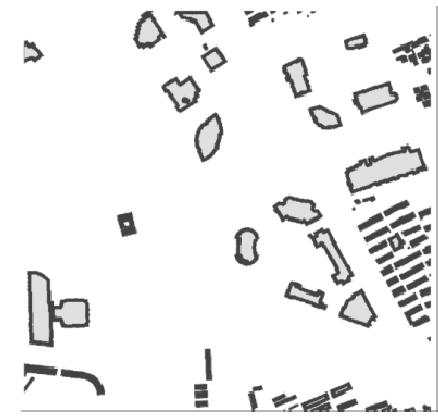

Figure 8: Lujiazui (CBD), Shanghai, PVR $=43 \%$.

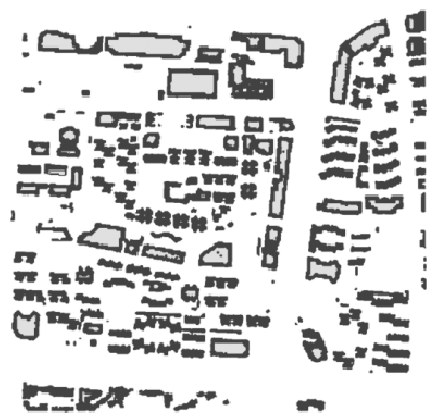

Figure 9: Tianhe, Guangzhou, PVR $=66 \%$. 
organised around numerous courtyards of all scales that allow a much better interface with the outside, and a passive volume ratio higher than $80 \%$. The analysis of the building size distribution and of the courtyards size distribution shows that the two historical urban fabrics display a high scale hierarchy, close to an optimal power law distribution [2].

Urban scale-free complexity is a way to optimise passive volumes in the urban fabric. Urban complexity is not about scattering numerous small elements, but on the contrary about respecting an adequate scale hierarchy: a small number of big buildings and courtyards, a medium number of medium size elements, and a big number of little elements. Modernist urban fabrics based on one are structurally speaking unsustainable. On the contrary, urban fabrics based on several scales (up to three or four fundamental scales in figures 10 and 11) allow optimizing crucial parameters for sustainability, such as the passive volume ratio.

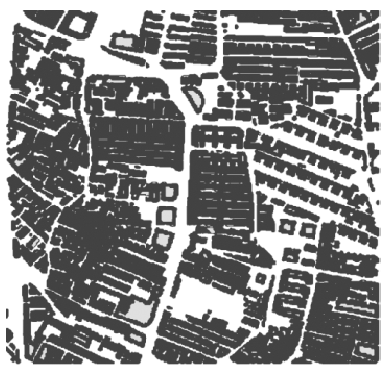

Figure 10: $\quad$ Lilongs, Shanghai PVR > 80\%.

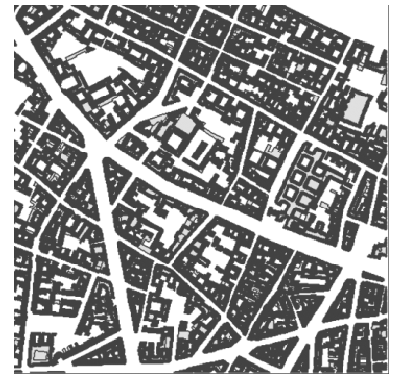

Figure 11: Paris district, $19^{\text {th }}$ century, PVR > $80 \%$.

\section{A climate dependant trade-off between passive volumes and $\mathrm{S} / \mathrm{V}$ ratio}

Along with the passive volume ratio, the building envelope/volume ratio widely impacts on urban sustainability. By widely influencing the structural needs (in heat, cooling, light or air) of buildings, they both widely influence the associated energy needs. As we explained earlier in this paper, a low $\mathrm{S} / \mathrm{V}$ ratio was advocated in the 70s by thermal engineers in cold countries: the more compact the better.

These two fundamental parameters are somehow antagonist. Table 1 displays the $\mathrm{S} / \mathrm{V}$ and passive volume ratios for the 6 theoretical neighborhood presented earlier in this paper. The more compact (small S/V ratios), the lower the passive volume ratio.

Table 1: $\quad$ S/V and Passive volume ratios for 6 theoretical neighborhoods.

\begin{tabular}{ccccccc}
\hline Type of neighborhood & $\begin{array}{c}\text { One } \\
\text { Block }\end{array}$ & $\begin{array}{c}\text { 1-level } \\
\text { courtyard }\end{array}$ & 9 blocks & $\begin{array}{c}\text { Linear } \\
\text { Buildings }\end{array}$ & $\begin{array}{c}\text { 2-levels } \\
\text { courtyards }\end{array}$ & $\begin{array}{c}\text { 3-levels } \\
\text { courtyards }\end{array}$ \\
\hline $\begin{array}{c}\mathrm{S} / \mathrm{V}\left(\mathrm{m}^{-1}\right) \\
\begin{array}{c}\text { Passive volume ratio } \\
(\%)\end{array}\end{array}$ & 0.08 & 0.10 & 0.13 & 0.12 & 0.12 & 0.19 \\
\hline
\end{tabular}


In septentrional latitudes, simple buildings with big courtyards are more adapted to the cold climates. They display a "good" S/V ratio - that is a small one - that limits thermal losses.

On the contrary, in hot and arid climates - the medinas of Sfax or Marrakech (fig. 12) for instance displays more than 1000 small courtyards on 24 ha - the main objective is not to limit thermal losses through the envelope but to insure passive ventilation and cooling. The "good" S/V ratio is a high one that increases passive volumes while protecting the inside and outside spaces from direct light and solar radiation. In this context, according to Ratti et al. [12], several authors such as Fahty [13] and Bahadori [14] claim that small courtyard allow the creation of an open sheltered zone, the adoption of ingenious natural cooling strategies, the protection against wind-blown dustor sand and the mitigation of the effects of solar excess.

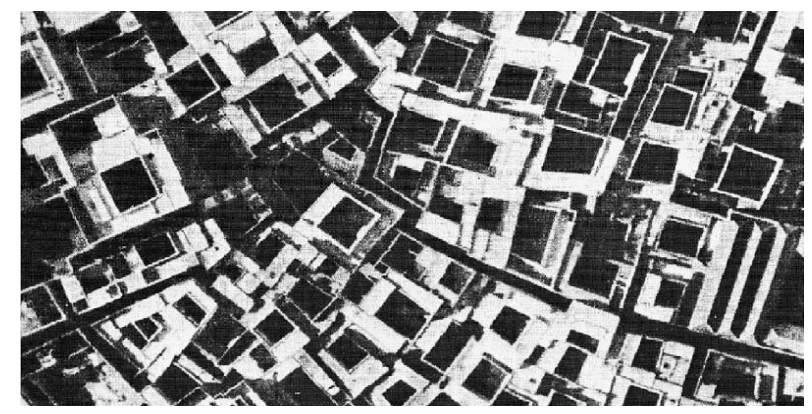

Figure 12: $\quad$ Small courtyards in central Marrakech [12].

The benefits of high $\mathrm{S} / \mathrm{V}$ ratios in hot climates are also related to inertia phenomena. Indeed, the order of magnitude of inertia phenomena directly correlates with the amount of material used in the buildings - notably the walls and thus to the surface of the envelope. According to Ratti et al. [12] the high thermal mass can be used to store heat during the day to benefit from it during the cooler nights. The maximization of $\mathrm{S} / \mathrm{V}$ ratios acts as a heat sink.

Today, with the rise in insulation standards and internal gains, the most important concerns in energy consumption have shifted to lighting and mechanical ventilation, for which the effects of urban geometry are different and even reversed. To maximize natural light, the passive volume needs to be increased and hence the compactness diminished. The impact of these values needs anyway to be put into perspective by an analysis separating size and form factors. Indeed, the $\mathrm{S} / \mathrm{V}$ ratio can be broken down for buildings or groups of connected buildings, into:

$$
\frac{\mathrm{S}}{\mathrm{V}}=\frac{1}{\mathrm{~V}^{1 / 3}} \cdot \frac{\mathrm{S}}{\mathrm{V}^{2 / 3}}
$$

In this equation $\frac{1}{V^{1 / 3}}$ represents the building size factor (the bigger the building, the smaller this factor) and $\frac{\mathrm{S}}{\mathrm{V}^{2 / 3}}$ is an adimensional factor that describes the form 
of the building. This breakdown makes no sense on the texture scale. The impossibility, on the texture scale, of separating size effects from form effects in the S/V parameter leads to a considerable loss of information on an essential aspect of the texture. Here we see that the volumetric compactness of the texture is an overly simple parameter because it does not allow us to apprehend the "grain" of the texture, that is, the fact that the texture is composed either of many small buildings that can be combined in a complex, continuous way (which, due to the contiguity, leads to a good factor of compactness), or of large discontinuous buildings (which also leads to a good factor of compactness but degrades other energy parameters, like daylight availability or natural ventilation potential).

\section{Conclusions}

A proper urban complexity is a way to improve the passive volume ratio, and thus to optimize the interface between the city and the outside, and to benefit from natural lighting, cooling, ventilation and passive solar gains. This paper shows how fractal patterns may help in optimizing the passive volume ratio. It should be kept in mind, however, that the passive volume is only a potential: these passive areas must be designed in a technologically efficient way, notably using smart bioclimatic solutions like those that enable light control through sensors that prevent overheating in summer, and heat loss in winter. Combining smart bioclimatic façades with good thermal insulation makes it possible in part to neutralize the geometric contradiction in optimizing the form of the texture. Indeed, there is no universal answer to the question of optimal urban texture, which depends on climate and latitude.

Pushing the thought further, this approach aiming at optimizing the urban envelope may also have implications on the renewable energy potential of urban structures. An optimized and complex interface on the district and city scale is a way to increase, with the same land footprint, the available envelope area, and thus the available area for solar energy. Complexification of urban structures may thus also reveal to be a part of the answer to the higher land footprint of renewable energy compared to the one of fossil fuels.

\section{References}

[1] D. Raydan, C. Ratti, and K. Steemers, "Courtyards: a bioclimatic form?,” in Courtyard Housing: Past, Present \& Future. New York: Taylor and Francis, 2006, pp. 135-145.

[2] S. Salat, Cities and Forms, On Sustainable Urbanism.: Hermann, 2011.

[3] S. Ozkan, "Courtyard: a typology that symbolises a culture.," in Courtyard Housing: Past, Present and Future. New York: Taylor and Francis, 2006, pp. 15-29.

[4] B. Fletcher, A history of architecture on the comparative methods. London: Batsford, 1954. 
[5] N. Baker and K. Steemers, "LT Method 3.0 - a strategic energy-design tool for Southern Europe,” Energy and Buildings 23, pp. 251-256, 1996.

[6] C. Ratti, N. Baker, and K. Steemers, "Energy Consumption and Urban Texture,” Energy and Buildings 37(7), pp. 762-776, 2005.

[7] M. Batty and P.A. Longley, Fractal cities: a geometry of form and function. London Academic Press, 1994.

[8] Salingaros N.A. and B.J. West, "A universal rule for the distribution of sizes," Environment and Planning B: Planning and Design, vol. 26, pp. 909-923, 1999.

[9] N.A. Salingaros, “Complexity and Urban Coherence,” Journal of Urban Design, vol. 5, pp. 291-316, 2000.

[10] S. Salat and L. Bourdic, "Power laws for energy efficient and resilient cities,” Procedia Engineering 21, pp. 1193-8, 2011.

[11] S. Salat and L. Bourdic, "Scale Hierarchy, Exergy Maximisation and Urban Efficiency,”, ELCAS2, Nisyros, 2011.

[12] C. Ratti, D. Raydan, and K. Steemers, "Building form and environmental performance: archetypes, analysis and an arid climate," Energy and Buildings 35, pp. 49-59, 2003.

[13] H. Fathy, Natural Energy and Vernacular Architecture. Chicago: The University of Chicago Press, 1986.

[14] M.N. Bahadori, "Passive cooling systems in Iranian architecture," Scientific American 2 (238), pp. 144-52, 1978. 